\title{
Meditaciones en torno a una casa (española de la Posguerra): La poética doméstica en las obras de Amalia Avia y Carmen Martín Gaite
}

\author{
Reflexions about a (Spanish postwar period) home: \\ Domestic poetry in Carmen Martín Gaite and
} Amalia Avia

Eva ASENSIO CASTAÑEDA

Universidad Europea de Madrid

Recibido: 18-IV-2015 / Aceptado: 15-VII-2015

Resumen: El presente estudio analiza comparativamente las obras de Amalia Avia y Carmen Martín Gaite; el modo en que ambas mujeres conciben y representan la temática del interior doméstico, siendo la casa el eje a través del cual articulan sus discursos expresivos. Su personal representación artística nos sirve de medio testimonial para retratar y conocer el contexto y la situación de la mujer en la España de la posguerra.

Los resultados son una serie de hallazgos, aspectos comunes, en sus obras, que ponen de manifiesto la notable influencia que este contexto social y político tuvo en la creación de las mujeres artistas contemporáneas españolas.

Palabras clave: Amalia Avia, Carmen Martín Gaite, Posguerra española, Realismo, Interior doméstico, Creatividad femenina.

ABstRACT: The purpose of this work is the comparative analysis of the works of Amalia Avia and Carmen Martín Gaite; specifically the way in that both women conceive and represent the topic of the domestic interior, the house being the axis through which to verbalise their expressive discourse. Furthermore, their personal artistic representation, serves as a testimonial method to portray and understand the context and situation of women in Spain in the 40s and 50s of the last century.

All of them show the remarkable influence that this social and political context had on the creations of contemporary Spanish women artists.

Key words: Amalia Avia, Carmen Martin Gaite, Spanish postwar, Realism, Home interior, Female creativity.

El presente estudio es un análisis comparativo entre la obra pictórica de la artista plástica Amalia Avia y la de la escrito- ra Carmen Martín Gaite, -concretamente en su novela Entre Visillos-, sorprendentemente análogas en estilos, contenidos y lenguajes 
expresivos, y no sólo desde el punto de vista artístico, sino también vivencial y personal de ambas ${ }^{1}$.

\footnotetext{
${ }^{1}$ Desde el punto de vista metodológico, por tratarse de un tema de creatividad femenina y relaciones de género, nos hemos basado para este estudio en la historiografía de género y la historia social. En cuanto a las fuentes manejadas, son de diversa procedencia. Para el análisis de Carmen Martín Gaite: Su novela, Entre Visillos, Barcelona, $1^{\mathfrak{a}}$ ed., 1958. Manuales publicados sobre las características de la novela de esta autora, textos sobre el contexto político, social y cultural de la España de la posguerra y otras obras publicadas por Carmen Martín Gaite: R. MARCUS, "Carmen Martín Gaite y la mujer hotelera", en M. ALMELA BOIX, M. GARCÍA LORENZO, H. GUZMÁN, M. SANFILIPPO (coords.), Mujeres a la conquista de espacios, Madrid, 2012, pp. 187201 y E. SAMARTI," El espacio de lo privado: los incentivos en la ventana en los cuentos de Carmen Martín Gaite (1953-58)", en M. ALMELA BOIX, M. GARCÍA LORENZO, H. GUZMÁN, M. SANFILIPPO (coords.), Op.cit., pp.301-310; M. L. GAZARIAN GAUTIER, “Conversación con Carmen Martín Gaite en Nueva York", Insula, no 411, 1981, pp.10-14; C. MARTÍN GAITE, La búsqueda de interlocutor y otras búsquedas, Barcelona, 1982; M. CARBAYO ABENGÓZAR, Buscando un lugar entre mujeres: buceo en la España de Carmen Martín Gaite, Málaga, 1998; E. MARTINELL GIFRE, El mundo de los objetos en la obra de Carmen Martín Gaite, Cáceres, 1996; C. ALEMANY BAY, La novelística de Carmen Martín Gaite, Salamanca, 1990; J. JURADO MORALES, Del testimonio al intimismo: los cuentos de Carmen Martín Gaite, Cádiz, 2001; ÍDEM, La trayectoria narrativa en Carmen Martín Gaite (1925-2000), Madrid, 2001; R. ARIAS CAREAGA, Escritoras españolas (1939-1975): poesía, novela y teatro, Madrid, 2005. Para las relaciones de género en la posguerra, lecturas sobre historia de mujeres y teoría de género: $\mathrm{C}$. MOLINERO, "Silencio e invisibilidad: la mujer durante el primer franquismo", Revista de Occidente, $\mathrm{n}^{\mathrm{o}}$ 223, 1999, pp.63-82; VV. AA., Mujeres y hombres en la España franquista: sociedad, economía, política y cultura, Madrid, 2003; A. CABALLÉ, El feminismo en España, la lenta conquista de un derecho, Madrid, 2013. La antropología cultural en relación con el espacio y la identidad femenina también está presente en este capítulo y es un elemento clave en la obra de las dos artistas: A. REDONDO GOICOECHEA y M. L. LLEDÓ PATIÑO, "Las imágenes de las mujeres en las novelistas de posguerra", en Mujeres y hombres en la España franquista: sociedad, economía, política y cultura, Madrid, 2003; J. ALCOLEA, Los niños de la guerra, Madrid, 1983; J. BACHELARD, La poética del espacio, México, 1975; K. M. BARAÑANO LETAMENDIA, "El concepto de espacio en la filosofía y la plástica del siglo XX", Kobie Bellas Artes, no 1,1983, pp. 137-224; O. DA ROCHA ARANDA, El modernismo en la Arquitectura madrileña. Génesis y desarrollo de una opción ecléctica, Madrid, 2009; L. MCDOWELL, Género, identidad y lugar,
}

El contexto político y cultural de la posguerra española y primer franquismo (entre 1939 y 1959) que les tocó vivir, así como la situación social de las mujeres, están recreados en sus obras que, además de por su calidad, son importantes por el valor testimonial e histórico que tienen. Se trata de otra visión de la posguerra contada desde la mirada de la mujer, desde otra perspectiva. En este contexto era frecuente que las mujeres artistas tuvieran problemas, originados por la desigual laboral y social, y no gozasen de las mismas oportunidades y recursos para poder dedicarse a la profesión de pintora o escritora. En este mundo la mujer apenas tenía cabida, pues la consideración profesional de la mujer era casi inexistente y sus funciones estaban relegadas a las de esposa y madre. El "modelo ideal" establecido por la Sección Femenina de la Falange e impulsado por el gobierno franquista no contemplaba que la mujer casada trabajase.

El hombre representaba el ámbito público del trabajo y la mujer el privado y reducido a la casa. Este mundo íntimo y femenino, donde las mujeres pasan el mayor tiempo y se relacionan entre sí, tiene su máximo exponente formal en la temática del

Madrid, 2000; P. MAYAYO, Historia de mujeres, historia del arte, Madrid, 2003; A. MOLES, Teoría de los objetos, Barcelona, 1975; A. SERRANO DE HARO, Mujeres en el arte. Espejo y realidad, Barcelona, 2000; J. UZCÁTEGUI ARÁUJO, El imaginario de la casa en cinco artistas contemporáneas, Madrid, 2011; M. VITTA, El sistema de las imágenes, Estética de las representaciones cotidianas, Barcelona, 2003. En cuanto a los contenidos de Amalia Avia, además de sus Memorias, De puertas adentro, Madrid, $1^{1}$ a ed., 2004, hemos revisado su trayectoria artística, los catálogos de las exposiciones individuales y colectivas más importantes desde su primera exposición en 1959, la antológica en el Centro Cultural de la Villa en 1997, hasta la última individual en 2013 celebrada en la Real Escuela de Bellas Artes de San Fernando, así como sus colectivas más destacadas y la última, celebrada en 2014 en la Fundación Caja Canarias, Visiones de la realidad. Destacamos también, para el estudio del denominado por la crítica especializada "grupo de realistas madrileños”, la publicación: J. TUSELL, “Compañeros en Madrid: Anatomía de un grupo generacional", en AA.VV, Otra realidad, compañeros en Madrid. Catálogo exposición, Madrid, 1992, 70-148. 
interior doméstico. Es un tema esencial para comprender el mundo simbólico y objetual en el que se desarrollaba la niñez y juventud de las mujeres españolas de la posguerra. Ese mundo íntimo y muy personal que las rodeó, en el que crecieron Amalia Avia, Carmen Martín Gaite y muchas mujeres de su generación, y que tan a menudo han recreado en sus cuadros de interior y de objetos domésticos y, en su narrativa, la segunda artista, es el que nos proponemos desvelar a través del estudio comparativo de sus obras. "Carmen Martín Gaite es otro de los exponentes máximos de la novela de posguerra y propone modelos de mujer que se van transformando a medida que su autora va recorriendo las etapas diferentes de su vida. Desde un punto de vista diferente, el de la sociedad de una provincia pequeña. Sin embargo, el viaje personal que realizan sus protagonistas será el mismo que el de sus compañeras de generación. El viaje personal hacia la propia identidad" ${ }^{2}$.

A través de esos ambientes caseros y en sus memorias De puertas adentro, Amalia Avia (1930-2011), nos desvela sus sentimientos y parte de sus recuerdos de infancia y juventud. La temática no es en absoluto nueva, pero si es peculiar el modo en que es revivida por la pintora. Carmen Martín Gaite (1925-2000) también concedió gran protagonismo en su obra al mundo de los objetos, a la realidad cotidiana y familiar que nos rodea y al espacio interior, recurriendo también a un lenguaje realista caracterizado por su humanismo.

Ciertamente, la razón de estas coincidencias radica básicamente en que ambas mujeres comparten contexto, contemporaneidad; pertenecen a la misma generación de artistas de la posguerra española. Analizando sus obras comenzamos a ser conscientes del hallazgo que supone el hecho de las numerosas similitudes que hay. La una y la otra provienen de provincias castellanas -Amalia Avia nació en Toledo -Santa Cruz de

${ }^{2}$ A. REDONDO GOICOECHEA y M. L. LLEDÓ PATIÑO, Op. cit., p.258.
Zarza- y Carmen Martín Gaite en Salamanca- y ambas se marcharon con sus familias a Madrid durante su infancia donde estudiaron; se formaron en sus respectivos campos artísticos, se casaron, vivieron y desarrollaron su obra; también comparten y reconocen pasión y entusiasmo por Madrid y en su temática es muy importante esta ciudad.

Reciben el importante influjo de un grupo de amigos de su misma generación, que no componen grupo como tal, pero si comparten idénticas inquietudes artísticas y literarias. La amistad que inician en los años cincuenta perdura el resto de sus vidas -en el caso de Amalia Avia nos referimos al "grupo de realistas madrileños" y en el de Carmen Martín Gaite al compuesto por Jesús Fernández Santos, Rafael Sánchez Ferlosio, Alfonso Sastre, Medardo Fraile y Josefina Rodríguez-. Ambas artistas conocieron a sus futuros maridos en un grupo de amigos artistas universitarios en los años 50, quienes, en ambos casos, son también artistas y en el mismo campo que ellas -el pintor Lucio $\mathrm{Mu}$ ñoz y el escritor Rafael Sánchez Ferlosio-. Supervivencia artística en un grupo de poder, en el que ellos gozan de un reconocimiento nacional e internacional y poseen amplias y exitosas trayectorias profesionales.

Por lo tanto, ambas pertenecen en sus respectivos ámbitos a un grupo generacional artístico de autores realistas madrileños; ellas son casos excepcionales en una España en la que la mujer carecía de reconocimiento profesional y son casos atípicos de mujeres que han triunfado en su ámbito aunque buscando un camino intermedio entre el reconocimiento y actuar masculino (creación) y la pasividad femenina.

En el caso de Avia, este grupo generacional de pintores y amigos lo componían: Lucio Muñoz, Antonio López, los hermanos López Hernández, Joaquín Ramo, Enrique Gran Amalia Avia, Esperanza Parada, María Moreno e Isabel Quintanilla ${ }^{3}$. Ellos con-

\footnotetext{
${ }^{3}$ Lucio Muñoz, Enrique Gran y Joaquín Ramo son pintores no figurativos, pero una de las peculiaridades
} 
curren en la Escuela de Bellas Artes de San Fernando de Madrid, donde cursaron la carrera, y ellas los conocieron en el estudio de Eduardo Peña y posteriormente, se casaron: Amalia Avia con Muñoz, María Moreno con Antonio López, Esperanza Parada con Francisco López Hernández e Isabel Quintanilla con Julio López Hernández. En los años 50 Amalia Avia, Esperanza Parada, Gloria Alcahud y Esperanza Nuere alquilaron juntas su primer estudio, hecho que Avia recrea en sus Memorias como uno de los momentos más especiales y felices de su trayectoria profesional.

Por la parte de Martín Gaite, “Aquel grupo de amigos y coetáneos de Ignacio Alcolea en que me vine a ver incorporada a mi llegada a Madrid, andaban como a tientas, partiendo de cero" ${ }^{4}$. Se conocen en la universidad que: "No nos dio mucho pero descubrimos la amistad, descubrimos que no estábamos solos, intercambiábamos libros, amábamos apasionadamente la literatura, la verdad, la justicia, la belleza. Nos amábamos a nosotros mismos, nos sentíamos unidos por un mismo destino que luego, irremediablemente, se dispararía en mil direcciones distintas" 5 .

Nuestras protagonistas se casaron y fueron capaces de compatibilizar su papel de madre con el de artista y mujer trabajadora; ambas escriben sobre ellas mismas -Entre Visillos tiene elementos autobiográficos en cuanto al origen salmantino de la novelista y Amalia Avia en sus Memorias cuenta detalladamente cómo fue su infancia y juventud como chica de provincia-; incluso hay rasgos de su carácter y personalidad que se parecen: ambas son vitales, alegres, inteligentes, comprometidas, críticas...,pero no se han encontrado referencias o evidencias por parte de la prensa y fuentes variadas manejadas en estos años sobre la posibilidad de que se

de este grupo generacional es la amistad que los une, no sólo lo pictórico.

\footnotetext{
${ }^{4}$ C. MARTÍN GAITE, La búsqueda..., p. 45.

${ }^{5}$ J. ALCOLEA, Op. cit., p. 21.
}

conocieran, es una posibilidad pero en cualquier caso no ha trascendido al ámbito público.

Cuando Martín Gaite presentó Entre Visillos al premio Nadal en los años cincuenta, lo hizo bajo el seudónimo de "Sofía Veloso" y sin que su marido supiera que concursaba. Actualmente es habitual que las mujeres publiquen y se desarrollen profesionalmente como los hombres, pero en los años de la posguerra el papel de la mujer estaba supeditado al ámbito del marido y el hogar. Progresivamente en el panorama nacional irán proliferando la lista de mujeres escritoras y pintoras, dedicadas plenamente a sus carreras, pero en este contexto de posguerra, las mujeres artistas debían conformarse con poder dedicar tiempo a su vocación de manera secundaria y cuando la crianza de los niños y del marido, de la familia, lo permitía. Un dato revelador del avance positivo de la consideración social de la mujer es que, a partir de los años setenta, principalmente, hayan podido las propias mujeres escribir sobre su propia historia y la de sus antecesoras. La historiografía de género es relativamente reciente. Las publicaciones centradas en el Arte realizado por mujeres suelen estar escritas por mujeres mayoritariamente, lo cual evidencia el camino que aún queda por recorrer.

Las dos artistas nos cuentan sobre el contexto de posguerra que han vivido, son hijas de la guerra; las interesantes y apasionantes memorias de Amalia Avia publicadas en 2004 son la crónica de la transformación política, social y cultural española a lo largo del siglo XX a través de la trayectoria vital de una niña que con el tiempo se convertiría en una conocida pintora. Carmen Martín Gaite, en su novela, también da su opinión crítica sobre esta sociedad en pleno cambio y a la vez encorsetada, rígida, sobre todo respecto a la mujer.

Ambas son, estilísticamente hablando, realistas sociales -sobre todo en esas primeras décadas de los cincuenta y sesenta-; pero, en el caso de Carmen Martín Gaite, ella 
escribe sobre mujeres, y su temática central -se puede decir que constante a lo largo de su trayectoria profesional- es la Mujer. En el caso de Amalia Avia lo es, pero no directamente y no sólo ella. Es decir, su obra, sobre todo a partir de los años sesenta, como dijo Cela, su pintura, es de ausencias, "pintora de ausencias" la llamó ${ }^{6}$, pero la huella del ser humano está siempre presente, la de la mujer en esos interiores domésticos que vamos a analizar y, sobre todo, y muy importante, el paso del tiempo y el intimismo en la obra de ambas.

También hallamos diferencias, lógicamente: En las publicaciones y estudios que hemos leído sobre Carmen Martín Gaite no se habla de ella como adscrita a un grupo generacional sino que se la estudia de forma individual"; en cambio, Amalia Avia -aunque tiene numerosas exposiciones individuales-, ha mostrado su obra otras tantas con sus compañeros realistas madrileños y muchos críticos la incluyen dentro del mismo. Como

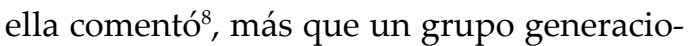
nal como tal se trata de un grupo de amigos que se conocieron a finales de los años cuarenta en Madrid y han estado juntos medio siglo, compartiendo espacios, experiencias y aprendizajes, pero sobre todo amistad.

$\mathrm{Su}$ vocabulario es realista, cada una en su campo, pero las dos tienen un lenguaje bastante similar desde el punto de vista expresivo y conceptual y, en esencia, conciben la creación y su proceso de un modo bastante semejante, pues han partido de una realidad vivencial muy similar desde niñas. Siendo mujeres, pudieron gozar de popularidad y alcanzar reconocimiento por parte de la crítica en vida y, casi desde el principio de sus trayectorias y a lo largo de toda su carrera profesional -en el caso de Marín Gaite

${ }^{6}$ C. J. CELA, en un texto escrito para la exposición de Amalia Avia en la Galería Pelaires de Palma de Mallorca en 1979.

7 Por ejemplo en M. CARBAYO ABENGÓZAR, Op.cit. o E. MARTINELL GIFRE, Op. cit.

${ }^{8}$ Durante la entrevista que le hicimos el 3 de julio de 2003 en su casa. cuando su novela Entre Visillos gana el premio Nadal en 1957 y en el caso de Avia, tiene su primera exposición individual en la Galería Fernando Fe en 1959-, en Madrid, ambas en los años 50, en plena posguerra, en unos momentos en los que las mujeres artistas no tenían apenas posibilidades ni visibilidad en el mercado del arte.

Evidencia de sus éxitos profesionales y reconocimiento son los numerosos artículos, reseñas, entrevistas y libros publicados por parte de la crítica y los estudiosos de sus obras y trayectorias -algo excepcional teniendo en cuenta que son mujeres artistas en un momento de silencio y ausencia de consideración social y cultural para las mujeres españolas $-{ }^{9}$.

En las últimas décadas han sido más las publicaciones, sobre todo en el caso de Carmen Martín Gaite, a raíz de la proliferación de los estudios e investigaciones sobre mujeres en España como consecuencia de la importancia que el feminismo ha cobrado a partir de los años 70. "El feminismo es una manera de recuperar ese desprestigiado mundo femenino mediante un análisis de nuestras experiencias como mujeres" ${ }^{\prime 10}$.

Estamos ante dos de las artistas de la posguerra española más prolíficas en sus respectivos ámbitos creativos y de mayor relevancia de la historia artística de género. Ambas han tenido una dilatada trayectoria

\footnotetext{
${ }^{9}$ Amalia Avia cuenta con casi dos centenares de exposiciones entre individuales y colectivas. Los críticos e historiadores más destacados han escrito sobre ella: Víctor Nieto Alcaide, Francisco Calvo Serraller, Javier Tusell o Valeriano Bozal. Respecto de sus compañeras de profesión, es la que tiene una producción artística más numerosa y experiencia profesional más dilatada junto con Carmen Laffón. Por su parte, Carmen Martín Gaite también tiene en su haber un legado muy importante. Recibió múltiples premios en reconocimiento a su obra: Gijón, Nadal, Nacional de Literatura, Príncipe de Asturias de las Letras, Castilla y León de las Letras, Nacional de las letras españolas, el Anagrama de Ensayo y la Medalla de Oro del Círculo de Bellas Artes. Sólo en novela cuenta con una veintena de publicaciones. Ambas artistas siguen estando de actualidad.
}

${ }^{10}$ M. CARBAYO ABENGÓZAR, Op. cit., p. 21. 
profesional -medio siglo de creación, desde la década de los cuarenta a los noventa del siglo pasado en el caso de Martín Gaite, y una década más en el caso de Avia-. Han sabido adaptarse, con humildad y sensatez, al paso del tiempo y mantenerse durante décadas, logrando, a través de sus lenguajes artísticos que analizaremos más adelante, que el lector y observador se identifiquen; quizá ese sea el secreto de su éxito, su visión veraz y cotidiana de la realidad.

Viendo algunos cuadros de interiores y con temática de objetos de Amalia Avia, y leyendo las cosas que la autora dice y escribe cuando habla de su pintura, surgió una inquietud a raíz de una curiosa asociación mental: el modo de pintar y de concebir la pintura de Amalia Avia nos recordó y la asociamos, en ciertos aspectos, al modo de escribir de Carmen Martín Gaite. Al leer o contemplar la obra de ambas -a las que admiramos, entre otras cosas, por su talento y personalidad estilística, por la sencillez, naturalidad y rotundidad expresiva-, a menudo nos viene a la cabeza la otra autora, como si se tratase de una asociación mental automática. Es como si hubiese entre ambas artistas un poso de familiaridad, agradable y que reconforta. La contemplación y lectura de las obras de ambas nos producen y transmiten, en ocasiones -y sobre todo cuando tratan los temas de interior y los objetos-, sensaciones y mensajes similares.

Esta sensación se acentúa aún más a raíz de la lectura de las memorias de Amalia Avia en 2004, De puertas adentro, en las que la pintora se nos revela por primera vez como escritora en un texto absolutamente sincero y sencillo como ella, de un enorme valor testimonial y documental como decíamos, retrato de las mujeres de la posguerra española, del papel que cumplían y debían desempeñar en la sociedad $\mathrm{y}$, también y no menos importante, una confesión abierta y directa de cómo ese compleja y difícil periodo fue vivido por una hija de la guerra. Estas memorias nos evidencian plenamente hasta qué punto en Amalia Avia hay una dependencia e interconexión entre sus recuerdos y vivencias y lo que pinta, cómo su vida como niña, joven y mujer se traslada a sus lienzos $\mathrm{y}$ a sus memorias, al igual que en la obra de Carmen Martín Gaite. Es un hecho que en el arte de género se produce esta continuidad, las artistas utilizan sus medios expresivos para contar quiénes son, qué han vivido y cómo sienten. En esto consiste el proceso de búsqueda de su identidad femenina. En el caso de estas artistas es, en los interiores domésticos de las casas, donde se materializa esta correspondencia en la que centramos el presente estudio.

"La casa" es el espacio privado que corresponde a la mujer -niña, joven, madre, adulta, anciana- en los años de la guerra civil y posguerra española; en donde se desarrolla y crece, donde ocurren todos los hechos principales de su vida y sus relaciones interpersonales. Es el núcleo central de la familia, territorio femenino.

Al principio pensamos en ello como en algo anecdótico, pero, llevada por la curiosidad, retomamos la lectura de Entre Visillos -la novela que más analogía presenta con el carácter de Amalia Avia y que, además, también trata la dualidad tan contrastada de las oposiciones "interior/exterior" de la casa pero también "realidad histórica o cuadro/subjetividad o interior" del autor y de los personajes $\mathrm{u}$ objetos, como en las obras de Amalia Avia-. Finalmente, revisadas las biografías y bibliografías de ambas, llegamos a la conclusión de que las dos artistas, cada una en su ámbito profesional, tienen un modo similar de concebir la vida, la sociedad, la política e incluso el Arte. Y lo que fascina más: la realidad nuestra, de los seres humanos, pero también de las cosas, de los objetos, son descritas por ambas haciendo uso de un lenguaje expresivo muy similar.

Para ambas, el repertorio objetual, el mundo de los objetos, ha sido un tema muy repetido y predilecto en sus obras. Utilizando, incluso, un tipo de recursos expresivos y descriptivos muy conectados: el de ambas es sencillo, directo, claro, evidente, rotundo... Amalia Avia y Carmen Martín Gaite son dos 
amantes de lo cotidiano, de nuestro mundo casero, de lo que en apariencia no es importante pero que nos hace sentir que nuestro entorno es nuestro. Además, todo ese mundo objetual que ambas retratan en sus obras representa el universo simbólico femenino de tres décadas en España, las de los años cuarenta, cincuenta y sesenta. Muchas mujeres de la generación de la posguerra se habrán sentido, en algún modo y en varias de sus descripciones, reconocidas o identificadas con alguno de los escenarios descritos por estas artistas.

Amalia Avia y Carmen Martín Gaite, decíamos, coinciden en sus temáticas. Nos referimos al interés que manifiestan por retratar la realidad que nos rodea; los espacios urbanos y rurales, lugares donde han pasado su infancia y juventud: Santa Cruz de Zarza, Salamanca y sobre todo Madrid, sus calles -a ambas les gusta mucho describir y representar Madrid, sus calles y barrios típicos, sus portales, su gente, porque es la ciudad que conocen, donde han vivido casi toda su vida y han desarrollado su obra, y cuando escriben y pintan sobre ella nos vemos como ellas caminando sus calles y compartiendo su modo de sentir y de mirarlo todo-; pero, sobre todo, son magistrales retratando lo familiar e íntimo, el espacio de los "interiores domésticos".

El interior doméstico es, pues, uno de los grandes temas de sus obras; un mundo que ambas conocen bien y por el que se sienten muy atraídas, al igual que otras mujeres hijas de la guerra, pues han crecido y madurado en esa dimensión desde su infancia. Es natural que se sientan tan cómodas al abordarlo y sepan representarlo con tanta credibilidad, pues en estos espacios privados e íntimos persisten y se funden sus sentimientos y memoria. Representan "un modo de expresión que proviene de ese haber aprendido mirar desde el interior"11, como dice Carmen Gaite, desde detrás de los visillos $\mathrm{y}$ las ventanas. $\mathrm{Y}$ es en esta cultura del interior y del silencio, desde la mirada femenina,

\footnotetext{
${ }^{11}$ M. L. GAZARIAU GAUTIER, Op. cit.,p.4.
}

donde reside su mayor coincidencia formal y de contenido.

Para las dos artistas la casa, ese espacio interior por antonomasia, es motivo de reflexión y representación artística constante; la conciben y representan desde una visión íntima y poética, estableciéndose una singular relación del lugar con el ser que la habita "En la organización de ese centro, nos vincula con nuestros semejantes más cercanos y nos crea el sentido de unión o pertenencia y de identidad"12.

La casa, además, es un espacio muy importante porque tiene mucho de nosotros, define nuestra identidad, costumbres y modo de habitar. Es el lugar donde nos relajamos y estamos protegidos frente al mundo exterior. Espacio y memoria se funden y confunden en el interior de las casas de Avia y Martín Gaite, se conciben como una extensión del propio cuerpo "estructura ligada a una construcción simbólica que da cuerpo a un conjunto amplio y rico en significaciones para el ser humano"13.

Sus interiores son el reflejo de cómo son y se comportan sus habitantes; sus objetos y muebles representan y nos describen cómo viven y qué costumbres tienen. Entre sus paredes se guardan recuerdos alegres y felices, pero también secretos, miserias y tragedias muy íntimas que se procuran guardar y preservar celosamente del exterior, de puertas afuera. El interior es vivido y sentido de diferente modo por sus moradores; nuestro modo de habitar nos define.

A través de la recreación de un rico mundo objetual en sus espacios, Avia y Martín Gaite nos conectan e integran dos ámbitos: la realidad física con la humana, logrando dar sentido a la dualidad y enigma interior "casa/alma", por lo que se podría decir

${ }^{12}$ M. ALMELA BOIX, M. GARCÍA LORENZO, H. GUZMÁN GARCÍA y M. SANFILIPPO (coords.), Op, cit, p. 27.

${ }^{13}$ J. UZCÁTEGUI ARÁUJO, Op. cit., pp. 21-22. 
que, sin duda, sus obras se caracterizan por un lenguaje basado en la poética doméstica ${ }^{14}$.

El peso que tiene este espacio para nuestra artista es muy considerable; en su autobiografía dedica una amplia extensión del texto a describirlo; ¿cómo fue su vida?, sus recuerdos de niñez y juventud van directamente asociados a las casas en las que ha vivido y que nos recrea con detalle y gran esmero y en este orden cronológico: la casa solariega de Santa Cruz de Zarza, la casa de la Calle Torrijos, de la Calle General Díaz Porlier de Madrid -como hemos dicho esta ciudad significa mucho para Amalia Avia-, tiene gran relevancia en su vida personal y profesional. Paradójicamente es en la de General Díaz Porlier, esquina con la Calle Goya, donde vive encerrada durante los años de la guerra y, a pesar de ello, le gusta esa amplia casa y tiene recuerdos muy felices de los vividos con su familia, de sus juegos infantiles con su hermana Maruja. Amalia Avia adora esta ciudad porque le permite salir del encierro y empezar a asistir a sus clases de pintura, hacer algo por ella misma, aprender lo que le gusta, tener amigos propios, montar su primer estudio con sus amigas, relacionarse con el exterior, formar parte de la esfera pública y tener reconocimientos y posibilidades como los hombres... -como para Natalia, de Entre Visillos y para la propia Carmen Martín Gaite, Madrid simboliza la oportunidad, la libertad-; la casa de la Calle Reina Victoria, la casa de Torrelodones, la casa de París, la casa de Mojácar en Almería y la última vivienda familiar en Madrid, de la que no hace referencias en sus memorias, donde vivió y siguió pintando felizmente con su familia, sus hijos y su marido Lucio Muñoz hasta su muerte (Fig.1).

\footnotetext{
${ }^{14}$ En las memorias de Amalia Avia, resulta llamativo el hecho de que dos de los capítulos -el tercero sobre la Casa de Santa Cruz y el veintisiete sobre la Casa de Torrelodones-, estén dedicados y lleven por título los nombres de dos de las casas en las que ha residido Amalia Avia durante su vida. Además, en el epílogo, encontramos otro dedicado a la casa de París.
}

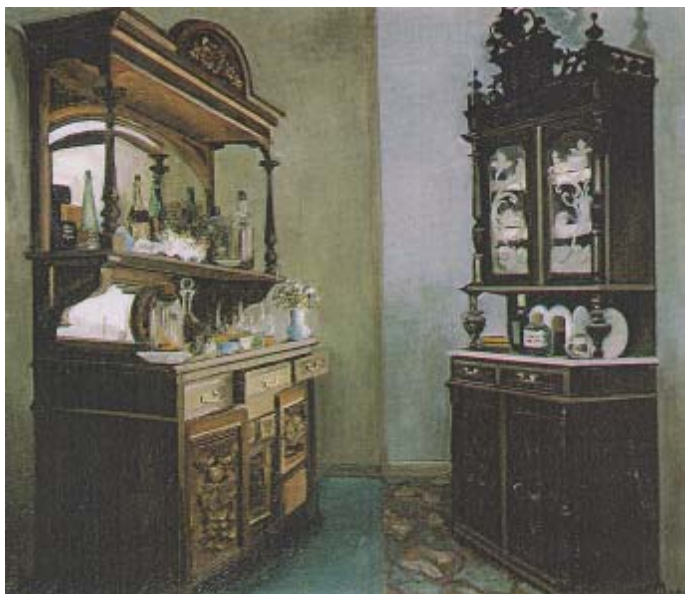

- Fig.1. Amalia Avia. “Dos aparadores”. Óleo sobre lienzo. 52x60cm. 1987. Foto: "Amalia Avia, cuadros", en D. MUÑOZ AVIA, lucioyamalia. com, consultado el 28 de mayo de 2015. URL: http://www.lucioyamalia.com/obra_amalia/ cuadros_amalia.php

En definitiva, no se trata sólo de un lugar físico para albergarse, sino que está llena de simbologías, recuerdos y significados asociados a toda su vida, como le sucede a Carmen Martín Gaite. El habitar cobra en sus obras su sentido más pleno..."la relación entre el individuo y el lugar, en el mundo posmoderno, en términos de los espacios físicos, mentales y socio-culturales que ocupa la mujer... Los espacios interiores son emblemáticos del espacio, tanto físico como simbólico, que ocupa la mujer en la obra de Carmen Martín Gaite"15.

La casa y su interior es motivo de reflexión estética, no solamente donde pasan más tiempo las mujeres de la posguerra. "El concepto se nos presenta en una doble vertiente, por un lado da cobijo al ser humano o al grupo familiar, estructura ligada a una construcción simbólica que da cuerpo a un conjunto amplio y rico en significaciones para el ser humano. Por otro, nos remite a un espacio fragmentado, ominoso, a un lugar de abyección, de carencia o de marginalidad"16.

${ }^{15} \mathrm{M}$. ALMELA BOIX, M. GARCÍA LORENZO, $\mathrm{H}$. GUZMÁN GARCÍA y M. SANFILIPPO (coords.), Op. cit., p. 187.

${ }^{16}$ J. UZCÁTEGUI ARÁUJO, Op. cit., p. 22. 
Sobre todo, en el caso de Amalia Avia, cobra especial importancia durante su niñez y juventud, en los años de encierro, miedo, hambre y silencio sufridos durante la guerra y posguerra en Madrid y en Santa Cruz de Zarza.

Encontramos en este punto una notoria similitud respecto a la idéntica asociación que hace Carmen Martín Gaite al conferir idéntico significado a la casa -casa natal y casa prisión- en Entre Visillos, de la que quieren liberarse y escapar Natalia y Julia; la primera para poder estudiar y la segunda para poder casarse; salir por fin de un espacio agónico y cerrado gobernado y protagonizado por mujeres de diversa jerarquía y condición -madre y administradora del hogar, tías y hermanas dominantes, doncellas, criadas, cocineras, costureras.-. Un espacio limitado por puertas, balcones, miradores, ventanas y visillos que protegen, aíslan y preservan a la mujer de lo que hay fuera; separan dos esferas incompatibles y opuestas para una mujer española de esos tiempos: el exterior y público, que pertenece al género masculino, con el interior $y$ doméstico, íntimo y privado, reservado a las mujeres (Fig.2).

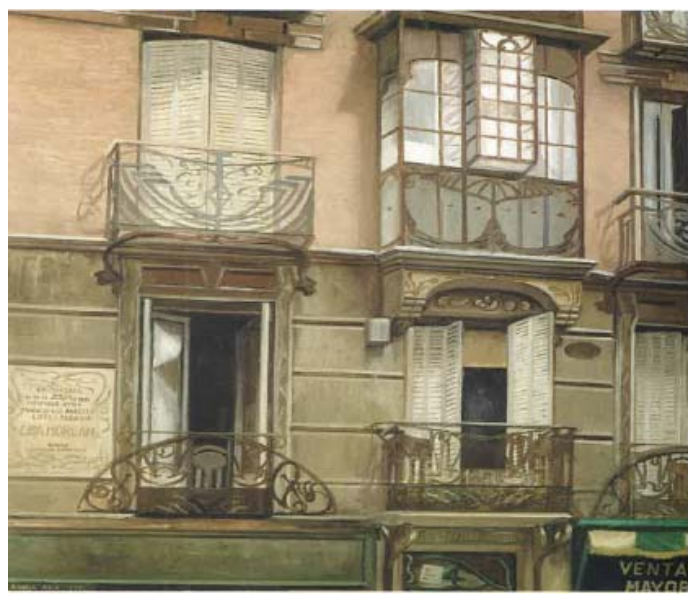

- Fig. 2. Amalia Avia. “La Casa de Lina Morgan“. Óleo sobre tabla. 60x60cm. 1994. Foto: "Amalia Avia, cuadros", en D. MUÑOZ AVIA, lucioyamalia.com, consultado el 28 de mayo de 2015. URL: http://www.lucioyamalia.com/obra_amalia/cuadros_amalia.php

Amalia Avia se detiene en varios momentos a describir cómo era esa casa fa- miliar y solariega de Santa Cruz de Zarza: grande, fresca, misteriosa y muy divertida para una niña por las posibilidades de juego que tenía, con sus múltiples rincones, en la que transcurrieron años de su infancia y juventud, que le dejaron una huella imborrable y con sabor agridulce por los graves hechos políticos que acontecieron. Casas que simbolizan y testimonian los duros años de padecimiento vividos con su familia durante la guerra y posguerra, reflejo de cómo este contexto afectó e influyó enormemente a los suyos y de qué modo caló en ella; cómo las relaciones familiares por tales circunstancias se tejieron entre ellos y se hicieron más silenciosas y restringidas tras el asesinato de su padre y el transcurso de la guerra civil y tras ella... pasando de la felicidad y la apertura antes de todo ello al silencio y el encierro en el interior de esa casa y la de Madrid de la calle General Díez Porlier número tres, a la que se trasladó con su familia.

"El nuevo piso era inmenso, tenía 13 habitaciones y una despensa...debió ser tan importante en mi infancia que ha supuesto una verdadera obsesión durante toda mi vida. Cuando paso por allí aún sigo mirando sus balcones, y daría lo que fuera por pasearme otra vez por sus habitaciones y pasillos. Lo primero por el recibimiento, lo que ahora llaman hall, bastante pequeño. Enfrente de la puerta, una mesa estrecha y alargada, imitación de español antiguo, atravesada por una tela roja con ribetes dorados que no la cubría por entero -"camino de mesa", así me parece que se llamaban estas telas-. Sobre ella había chocolateras, almireces y otros cacharros de cobre; debajo un inmenso asador, también de cobre, y arriba, cubriendo toda la pared, un gran tapiz. A derecha e izquierda partían dos largos pasillos; para separarlos e independizar un poco la entrada colgaban dos cortinas, una a cada lado. Si tuviera que elegir un símbolo de mi infancia, serían esas cortinas. (...) Al pasillo de la derecha daba el comedor y el cuarto de estar; la cocina, la despensa, el cuarto de las muchachas y el de la plancha; el dormitorio de mis padres, con un gabinete delante; y el cuarto de baño el único para esa 
inmensa casa y familia. La cocina era pequeña, fea y triste, iluminada casi siempre con luz eléctrica. (...) El cuarto de estar, en cambio, era grande y alegre, con un gran balcón que daba a la zona de la calle más cercana a Alcalá. La parte lindante con el pasillo, muy cerca de la cocina, sólo recibía la luz del balcón de la parte delantera. En ese primer espacio había un aparador vertical, de color canela, con puertas de cristales verdes.(...) El suelo de todas las habitaciones era de baldosas con dibujos y colores distintos en cada habitación. ¡Qué importancia tuvieron los suelos en mi infancia! Supongo que en ésto influyó bastante la guerra, porque nos obligó a permanecer en casa más tiempo de lo normal en un niño a nuestra edad. Para mí siempre serán algo muy evocador. (...) El cuarto de estar comunicaba con el comedor por unas grandes puertas de cristales. El comedor, por el contrario, era lujoso y confortable. No se comía en él más que en contadas ocasiones, pero en cambio se recibía allí a las visitas. Los amigos de mi padre y las visitas profesionales pasaban al despacho; las amigas íntimas o familiares de mi madre se sentaban con ella en el gabinete que tenía delante de su dormitorio; pero a las visitas, lo que se llamaba una visita, esas que llegaban ceremoniosamente sin avisar, y que a veces se quedaban durante horas, a esas se las recibía siempre en el comedor. (...) En el pasillo de la izquierda estaban los dormitorios de todos los hermanos y el despacho de mi padre, con la oficina de sus secretarios. Las dos partes de la casa, izquierda y derecha, eran completamente gemelas. Doblando el plano casi todo coincidía. Esto era así porque ocupaba todo el espacio que en otras plantas estaba destinado a dos viviendas. Nuestro cuarto era el último de ese lado, el más próximo a Goya. (...) El despacho me parecía muy bonito, con esos muebles complicados y negros que tenían tantas cosas: cabezas de dragones, bocas abiertas, patas torneadas que daba gusto acariciar y esos asientos de piel rematados con tachuelas en forma de margaritas...todo lo que había en el despacho me gustaba y atraía"17.

${ }^{17}$ A. AVIA, Op. cit, pp. 24-29. Esta casa fue la más importante para Amalia Avia, donde pasó la guerra y de
Es significativo el hecho de que ocupe una aparte importante de sus memorias teniendo en cuenta que pasó más de medio siglo desde entonces; pero es sorprendente la nitidez y la riqueza de detalles con las que nos describe y recuerda esas casas que indudablemente la marcaron como mujer y artista. A Amalia Avia siempre le gustó mucho leer y coser -las dos actividades principales de las mujeres que habitan estos interiores domésticos, las cuales son recogidas y mencionadas a menudo por nuestras artistas en sus obras; el modo habitual de pasar el tiempo junto con las visitas recibidas en el comedor-.

El hecho de ir al colegio y pasear, salir de casa, observar a la gente, le gustaba y atraía mucho, al igual que a Natalia la protagonista de Entre Visillos, pues suponía una oportunidad para tomar contacto con el exterior, escapar del encierro y tedio de la casa y alimentar su inquietud por aprender otras cosas más allá de la costura, los libros y los cotilleos de siempre... desde pequeña, Amalia Avia también se hace preguntas que a veces no puede responderse y no comprende su entorno...se refugia en la lectura, en la música -los cuentos de Celia y Cuchifritín, la radio, el flamenco y la música clásica serán otras de sus pasiones-. Posteriormente, en su juventud, lo hará en su producción artística, para no sucumbir a la realidad que les rodea, la limitación intelectual y social que corres-

la que más recuerdos conserva junto con la de su madre de Santa Cruz de Toledo. Esta casa responde a la tipología arquitectónica de corte historicista, consecuencia del proyecto del ensanche de Madrid, aprobado en 1860, que constituyó la ampliación más importante de la ciudad hasta la segunda mitad del siglo XX. Este tipo de arquitectura se adscribe a lo que se llamó modernismo madrileño ecléctico, que, como define, Ó. da ROCHA ARANDA, Op. cit., p.148, combina el equilibrio y simetría de las construcciones tradicionales con elementos decorativos novedosos, tales como el uso del hierro tanto en el exterior (fachadas y portales), que tanto gustaba pintar a Amalia Avia, como las rejas de los interiores (barandillas de escaleras o hierros de las puertas). Este tipo de vivienda doméstica simbolizaba una clase social de alta burguesía y cada estancia tenía también una significación y uso social diferentes. Hemos considerado oportuno incluir la descripción detallada que la pintora hace de ella por ser uno de los elementos claves de esta investigación. 
pondía a las mujeres de esa época; nuestras protagonistas son mujeres fuertes y con gran vocación artística, dotadas de personalidad e identidad propia y muy marcada, capaces de enfrentarse a esa realidad de miseria e ignorancia y superarla de otro modo, a través de sus creaciones artísticas.

También convergen en los tiempos históricos representados. Como hemos comentado, sus obras transcurren durante la posguerra y narran historias y escenas que suelen corresponderse con el tiempo real y presente de sus vidas acerca de la ciudad que conocen, los espacios por los que pasean o los interiores que han visto y en los que han vivido, los cuales les resultan muy cercanos y propios -Salamanca, por ejemplo, es la ciudad natal de Carmen Martín Gaite y la protagonista principal de su novela-. Al igual que Amalia Avia, pese a los acontecimientos vividos durante aquellos difíciles años, la recuerdan y reviven como una época feliz. En ello tuvo mucho que ver el estrecho vínculo familiar establecido, sobre todo con sus hermanas y madres, con las que pasaban la mayor parte de su tiempo, las cuales ejercieron una importante y positiva influencia sobre ellas.

Amalia Avia y Carmen Martín Gaite tienen la misma tendencia artística, son en su dicción realistas y, por añadidura, conciben la realidad y el realismo, en esencia, de igual modo, con un sentido social, humanista y poético, en el que el autor no es el protagonista y, sin embargo, hay mucho de él en la obra. Sus sentimientos se transmiten a través de sus obras y los sellos e identidad de ambas son inequívocos. Ambas tienen mucha personalidad artística y, aunque a nuestro juicio existan hermosas similitudes, cada una tiene un estilo muy personal y genuino en su medio de trabajo.

“En ello sobre todo, hay un modo de tratar el arte como un medio de expresión directa y personal, alejada de cualquier enfoque tradicional o académico. El arte aparece como un medio de testimonio y de reflexión. En España, buena parte de la expresión figurativa de muchas artistas de los años cin- cuenta y sesenta, como Amalia Avia, Isabel Quintanilla, Esperanza Parada o María Moreno, podrá relacionarse con un interés por reflejar lo doméstico. Aunque también este espacio interior fue un tema poseído de todas las connotaciones de encierro que un país bajo una dictadura puede presentar"18 -como lo es para Carmen Martín Gaite-.

En la iconografía objetual de Amalia Avia y Carmen Martín Gaite se encuentran analogías, decíamos, como es la expresión de su lenguaje, el método descriptivo que usan y la utilización de repertorios objetuales que coinciden, el tema del interior y el uso de objetos concretos y estancias domésticas con similar simbología, tales como mobiliario y adornos -ventanas, visillos, balcones, miradores, lámparas, sillones, mesillas, aparadores, pasillos, dormitorios...-.

Los objetos, en las obras de ambas, adquieren un importante valor testimonial y autobiográfico. En el caso de Amalia Avia representan recuerdos -en ocasiones tristes provocados por el contexto político, la guerra civil y la posguerra vividas en su niñezque le sirven principalmente para reflejar el paso del tiempo y la presencia del ser humano en sus obras; nuestro pasado pero también el presente, que se manifiesta a través del evidente uso y deterioro, o por la antigüedad de los objetos y muebles.

"En Amalia Avia es muy perceptible ese trasfondo trágico y, más todavía, el mecanismo de defensa a través de la defensa del reducto cotidiano de lo familiar y lo hogareño. (...) el hogar como reducto defensivo de la felicidad propia frente a la acechanza del mundo exterior"19.

"La casa -ha escrito Adolfo Castañoentraña toda una poética del espacio; el ca-

\footnotetext{
${ }^{18}$ A. SERRANO DE HARO, Op. cit., p. 113.

${ }^{19}$ Es importante aclarar una diferencia significativa entre las dos artistas. Si bien para Amalia Avia el interior de una casa y todo lo que contiene significa refugio, para Carmen Martín Gaite es todo lo contrario, encierro y asfixia. Ambas retratan espacios comunes pero el sentido que cada una le da es bien distinto, opuesto incluso.
} 
jón, los cofres, los armarios son refugios. Los rincones también. Todo lo que conforma una casa, el espacio interior, es una concha protectora que nos envuelve y nos cobija"20 (Fig.3).

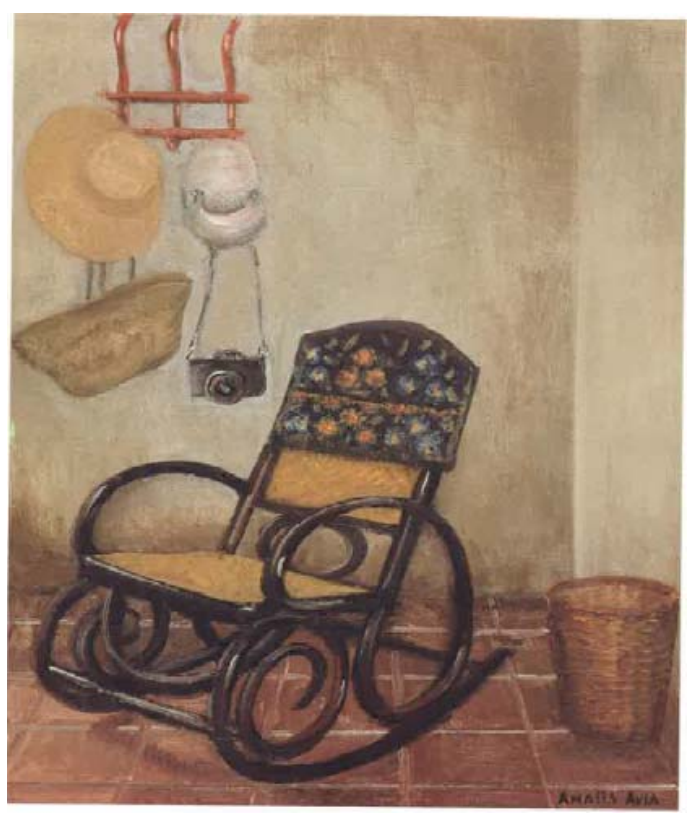

- Fig. 3. Amalia Avia. “Interior de Mojácar”. Óleo sobre tabla. 40x30cm. 1995. Foto: "Amalia Avia, cuadros", en D. MUÑOZ AVIA, lucioyamalia. com, consultado el 28 de mayo de 2015. URL: http://www.lucioyamalia.com/obra_amalia/ cuadros_amalia.php

Para Carmen Martín Gaite, también los objetos tienen ese significado y valor testimonial pero, además, los objetos y los ambientes que escoge le sirven y son utilizados como símbolos, son representación de estados de ánimo y sentimientos o reflejo de una determinada situación social, "Mitologías domésticas", como las denomina Amparo Serrano de $\mathrm{Haro}^{21}$.

“En un viejo sofá verde de mi casa de Salamanca donde me sentaba a leer cuentos y a soñar prodigios, a los siete, a los ocho, a los nueve años; vi el cuarto de jugar, las marionetas recortables, los tebeos; percibí el desor-

${ }^{20}$ J. TUSELL, Op. cit., p.79.

${ }^{21}$ Es un término empleado en la historiografía feminista y que Amparo Serrano de Haro utilizó en uno de nuestras entrevistas. den, la luz, el olor de la estancia aquella de los juguetes tirados por el suelo, los ruidos de la cocina colándose a través de la puerta"22.

Se trata de recursos hábilmente manejados que, también, en gran medida aumentan los efectos expresivos de las historias de sus personajes. Incluso -y en este aspecto conecta con los "juegos de oposiciones" que planteamos en el presente trabajo- le gusta recurrir a los términos y extremos, es decir, establecer juegos de oposición literarios ${ }^{23}$. Así, por ejemplo, el interior -de los hogaressimboliza el mundo cerrado, lo que nos asfixia y está en oposición al exterior (la calle) y el balcón, mirador o ventana son el tránsito entre ambos, el tenue espacio que los separa.

"Elvira se fue al despacho de su padre. Anduvo un rato mirando los lomos de los libros a la luz roja de la lámpara. Olía a cerrado. A la madre le gustaba que estuvieran los balcones cerrados, que se notara al entrar de la calle aquel aire sofocante y artificial. "Es una casa de luto"-había dicho. Elvira se asomó al balcón y respiró con fuerza"24.

En algún momento de las vidas artísticas de ambas, concretamente en los ideológicamente movidos años sesenta, años en los que en los órdenes cultural y artístico oficiales en España había cierto recelo en todo aquello que tuviese cierto contenido y reivindicación social, precisamente las dos artistas cultivaron una obra de mayor contenido social. De hecho, ambas en algún momento de sus trayectorias han definido sus obras dentro del realismo social porque son mujeres comprometidas con su tiempo y preocupadas por las mejoras sociales. En el caso de Amalia Avia, al igual que su marido, ha manifestado en ocasiones sus preferencias ideológicas y ha participado en el pasado en reuniones íntimas junto con otros

${ }^{22}$ C. MARTÍN GAITE, La búsqueda..., p. 184.

${ }^{23}$ En este sentido hay que mencionar la completa e interesante investigación llevada a cabo por E. MARTINELL GIFRE, El Mundo de los Objetos en la obra de Carmen Martín Gaite, Cáceres, 1996.

${ }^{24}$ C. MARTÍN GAITE, Entre visillos, p. 122. 
artistas donde se ha debatido sobre temas políticos, pero no ha habido nunca en Amalia Avia interés por la participación pública en actos políticos ni una intencionalidad política en su pintura; si bien es cierto que durante los años sesenta realizó cuadros con títulos y temas de claro contenido de denuncia social -obras como Manifestación, 1962; El penal de Ocaña, 1967; Lucha en la ciudad, 1966; El preso, 1967; etc-.

La obra de Carmen Martín Gaite es social en tanto en cuanto cuenta, critica y destapa la situación de la mujer de la posguerra española. Entre Visillos, por ejemplo, es un perfecto retrato de la mujer de capital de provincia con pocas aspiraciones, conformada y apocada, víctima de la tradición, la costumbre y lo que hay que hacer porque es lo que está establecido, lo que se espera y lo que está bien visto.

Comentamos antes que en la obra de Carmen Martín Gaite la mujer es, a la vez, protagonista y narradora de su propia historia. Ciertamente, existen elementos autobiográficos evidentes en su primera gran novela y, aunque no es la mujer como tema $\mathrm{u}$ objeto representado lo que las une, si es la visión que como mujeres y artistas comparten sobre la realidad vivida y contemplada que retratan en sus obras. Lo importante, en suma y en cualquier caso, es el tratamiento que de ésta y del mundo femenino ella hace en su producción literaria; su visión, concretamente en su novela Entre Visillos. La mujer es objeto y sujeto creativo en su caso.

Citando a Amparo Serrano de Haro, "el énfasis de la diferencia conduce a la contraposición como forma de diferenciación. Esta es, sin duda, la gran aportación de la visión femenina en la historia del Arte a partir de los años centrales del siglo pasado" 25 .

El tema de la mujer ha sido la gran preocupación de esta escritora. -Quizá este es uno de los pocos aspectos en los que no coinciden en el sentido de que Amalia Avia es mujer pero no pinta mujeres, aunque en

\footnotetext{
${ }^{25}$ A. SERRANO DE HARO, Op. cit., p. 16
}

muchos de sus interiores y hogares su presencia, aunque físicamente inexistente en ese escenario, se siente. Es como si se respirase en el ambiente la silenciosa huella de la mujer bien enseñada que, prudente y discreta, nos observase desde la habitación de al lado limitándose a mirar-, y el tema de la mujer le ha servido para hacer una crítica contra la situación tan limitada de la mujer española de los años de la posguerra y posteriores.

Por este motivo, muchos críticos consideran a Carmen Martín Gaite una escritora feminista. Sin embargo, ella siempre ha negado cualquier vinculación al feminismo. Sencillamente, lo importante es que esta mujer es una de las escritoras más importantes que tenemos y su trabajo, como dice Mercedes Carballo, "supone una importante e inestimable contribución a la literatura escrita por mujeres, literatura que, por otra parte, reivindica el mundo femenino desde un punto de vista femenino" ${ }^{26}$.

Carmen Martín Gaite, a través de la mujer, pero también, en gran medida a través del entorno de ésta, su familia, amigos, su ciudad, su casa, su cotidianeidad, sus costumbres y sus cosas -muebles, ropas, objetos, etc.- construye sus realidades y nos las transmite. Se podría decir que en la obra de las dos está presente la mujer pero de un modo diferente; silencioso en Amalia Avia y silenciada, en Carmen Martín Gaite. Y en ambos casos, la mujer es la autora y narradora. La falta de comunicación en nuestra sociedad, el silencio -y por extensión en el caso de la escritora la comunicación con el lector- ha sido una de las constantes preocupaciones para Carmen Martín Gaite. En su producción novelística y ensayística aparece esta preocupación por la búsqueda de un interlocutor, lo cual es resuelto por la autora con el establecimiento de un narrador que hace de hilo conductor de toda la obra, que se corresponde con uno de los personajes o incluso con la propia Carmen Martín Gaite, como sucede en Entre Visillos o

${ }^{26}$ M. CARBALLO ABENGÓZAR, Buscando un lugar entre mujeres: buceo en la España de Carmen Martín Gaite, Málaga, 1998, p. 18. 
en El Cuarto de Atrás, que tiene mucho de autobiográfico ${ }^{27}$. Ese interlocutor es el canal que utiliza la autora para transmitir su realidad y su modo de sentir al lector.

"Bueno, a mí y a todo el mundo, un interlocutor es lo que andamos buscando todos siempre. Piensa en toda esa gente que va a los psiquiatras para contarles su caso o que anda hablando sola por la calle. Si uno pudiera encontrar el interlocutor adecuado en el momento adecuado, tal vez nunca cogiera la pluma. Se escribe por desencanto de ese anhelo, como a la deriva, en los momentos en que el interlocutor real no aparece, como para convocarlo" 28 .

Amalia Avia y Carmen Martín Gaite no pintan ni escriben como se espera de una mujer; no responden a los estereotipos y convencionalismos tradicionalmente establecidos. Como dice Francisco Nieva en el caso de Amalia Avia:

“Las pintoras realistas -refiriéndose a las del grupo de pintoras realistas madrileñas- han sido las más audaces $y$, hasta en cierto sentido, las más masculinas. En todas late un curioso desafío. Amalia Avia tiene algo de Zola o de Dicenta femenino, pintando las puertas y las esquinas, las habitaciones $\mathrm{y}$ las tiendas de la ciudad desamparada y activa, con la crudeza gris de los días "diarios", de lo cotidiano machacado, lleno de rincones con el interés de la ruina. Visión que resulta lírica por la paradoja moderna de ser "fría" ${ }^{29}$.

${ }^{27}$ C. MARTÍN GAITE, El cuarto de atrás, Madrid, $1^{\text {a }}$ ed., 1973.

${ }^{28}$ M. L. GAZARIAU GAUTIER, Op. cit., p.1.Parece que tanto Amalia Avia como Carmen Martín Gaite, en algún momento de sus vidas, han recurrido a la pintura y a la escritura en momentos críticos personales, utilizando, cada una, su medio de expresión artística como válvula de escape o como salida de un estado anímico crítico (de evasión en el caso de Amalia Avia, que comenzó a pintar en su juventud para escapar de la tristeza que se vivía en la casa en la que pasó su niñez, y de posible huida de la soledad, en alguna ocasión, en el de Carmen Martín Gaite).

${ }^{29}$ F. NIEVA, “Una muestra fundamental”, en AA. VV., Otra realidad..., p.17.
Cada una en su parcela, estas dos artistas han hecho notables aportaciones al realismo pictórico y literario. No abundan vidas y trayectorias artísticas femeninas tan intensas y duraderas como las de ambas; no es habitual en nuestra historiografía de mujeres artistas encontrar ejemplos como los de Amalia Avia y Carmen Martín Gaite, que con seriedad y constancia han conseguido que su trabajo se reconozca y se premie como el de cualquier otro pintor o escritor, logrando abrirse camino en los complicados años de la posguerra y siguientes, cuando la incursión profesional de la mujer en el arte no era algo usual.

Es evidente en qué modo la España de la posguerra y la autarquía influyeron en la conformación de la identidad femenina y la personalidad artística de Amalia Avia y Carmen Martín Gaite. Sus personalidades creativas tienen mucho de testimonio y evocación de una situación cultural y artística complicada para las mujeres, que veían sus sueños truncados, sin recibir apoyo ni tener las mismas oportunidades formativas $\mathrm{y}$ beneficios sociales ni laborales que sus compañeros masculinos. Las dos son dos casos bastante excepcionales en este sentido, pues lograron salir adelante y conseguir un reconocimiento en sus ámbitos profesionales.

En cierto modo, y sobre todo para los que, como ellas, fueron los jóvenes de la posguerra llenos de fortaleza e ilusión, durante mucho tiempo estas admirables mujeres y artistas han contribuido enormemente en la reconstrucción de nuestro pasado, de nuestros recuerdos y de nuestro universo cotidiano y humano. Amalia Avia y Carmen Martín Gaite proyectan, desde su singular "poética doméstica de puertas adentro", un testimonio vital y creativo que procede de lo más profundo, de sus sentimientos y recuerdos, sin tapujos, desde el interior. Su "experiencia del espacio" se basa en tres constantes: el paso del tiempo, la pervivencia de la memoria y la identidad femenina. 